\title{
A EXPLORAÇÃO DE ÁREAS DE VEGETAÇÃO PROTEGIDA NA BACIA DO RIBEIRÃO DA CONFUSÃO, RANCHARIA - SP
}

\author{
Lucas Prado Osco ${ }^{1}$, Marcos Norberto Boin ${ }^{2}$ \\ ${ }^{1}$ Engenheiro Ambiental, pela UNOESTE, Aluno Especial do Mestrado em Meio Ambiente - UNOESTE. ${ }^{2}$ \\ Docente do Mestrado em Meio Ambiente - UNOESTE. E-mail: lucas prado 123@hotmail.com
}

\section{RESUMO}

O presente trabalho intitulado de "A exploração de áreas de vegetação protegida na bacia do ribeirão da Confusão, Rancharia - SP" tem por finalidade apresentar a importância de coberturas vegetacionais, suas funcionalidades e contribuições para a biodiversidade, abordando características paisagísticas da região ao qual está localizada a bacia do ribeirão da Confusão, juntamente com uma apresentação das condições atuais da bacia após a implementação de projetos ambientais, como o de "Reviva Confusão". O trabalho buscou informações em pareceres técnicos e trabalhos previamente realizados sobre a bacia, ao qual se levantou informações relacionadas às áreas de coberturas de vegetação natural, a delimitação da área de preservação permanente, assim como uma análise por vistorias in loco as áreas de preservação ambiental, diagnosticando-as. Por fim, elaborou-se uma discussão referente às condições atuais destas áreas, juntamente com a capacidade de obter-se uma melhor sustentabilidade ambiental para a região da bacia, de forma a garantir um melhor aproveitamento dos recursos naturais e da qualidade ambiental por parte dos proprietários e moradores situados em seu interior.

Palavras-chave: Ribeirão da Confusão; Projeto Reviva Confusão; Área de Preservação Permanente.

\section{INTRODUÇÃO E OBJETIVO}

Historicamente há uma crescente preocupação no que diz respeito às condições ambientais a que o ser humano vive. O assunto meio ambiente é de importância para todos, afetando o desenvolvimento social e econômico. Por conta disto, muito do que se discute sobre a finalidade e os serviços que determinada porção da natureza oferece para o homem reflete na elaboração e alteração de diversas leis ambientais ao decorrer dos anos.

De acordo com FRANCO (2005), tamanha preocupação é decorrente do fato de que as características ecológicas, geográficas e morfológicas abrigam uma rica diversidade, o que permite a conexão de remanescentes florestais, de reservas legais e unidades de conservação, favorecendo o planejamento de espaços ecologicamente sustentáveis. A cobertura vegetal apresenta uma série de influências positivas na dinâmica do meio ambiente.

Segundo VARJABEDIAN (2002), áreas compostas por matas ciliares representam grande importância para o controle climático, seja este da poluição do ar, de uma melhoria na qualidade estética, em efeitos decorrentes da saúde mental e física da população, um aumento no que se diz respeito ao conforto ambiental, além de uma valorização das áreas para o convívio 
social e econômico para as áreas rurais, juntamente com a formação de uma memória e um patrimônio cultural. Quanto da importância da cobertura vegetacional em uma área para a conservação do solo, esta age como um dos principais fatores, pois, por conta da presença de folhas, há proteção física e estabilizadora, que age como interceptadora dos impactos ocasionados pela precipitação. A presença de matéria orgânica, que por origem se dá nos detritos provenientes das quedas de folhas, promove condições estruturais adequadas ao solo, reduzindo ações erosivas.

Porém, dentre os demais benefícios resultantes da presença de uma mata ciliar, fazse possível à melhoria da qualidade dos recursos hídricos, por ajudar na retenção de diversos produtos contaminantes, como também da quantidade de sedimentos. De acordo com DAVIDE et AL. (2000), matas ciliares podem reter até cerca de 80 a $90 \%$ de fósfoto (P) e nitrogênio (N), elementos os quais, em excesso, resultam em um crescimento acelerado de algas e plantas aquáticas, em um processo denominado de eutrofização, onde a quantidade de oxigênio (O) é alterada, trazendo por consequência uma redução de peixes e demais formas de vidas presentes no corpo d'água, além de elevar o custo no tratamento deste recurso quando voltado para o abastecimento público. Ainda segundo o mesmo autor (DAVIDE et AL. 2000), como benefício da presença de matas ciliares, há estabilização de margens dos rios, já que a taxa de infiltração de água no solo pode variar em até 10 a 15 vezes maior do que em uma pastagem, e até 40 vezes a mais que em um solo descoberto.

A proteção a qual as matas ciliares exercem é essencial para a manutenção ecológica de todo o meio ambiente, principalmente tendo em vista a ação de aspectos ambientais que, decorrentes de sua interação, resultam em alteração da qualidade ambiental. Por consequência disto, todo o aspecto de alteração da qualidade tanto da água quanto do solo deverá interagir juntamente com o aspecto da supressão vegetacional. Esta inter-relação por parte destes fatores como o solo, a vegetação, a fauna e a hidrologia, irão refletir na qualidade em que o meio ambiente se encontra, portanto a conservação de áreas florestais é de suma importância.

Em razão desta importância ambiental, políticas públicas juntamente com ações organizacionais comprometem-se com a restauração das matas ciliares e com a conservação de áreas de preservação permanente e de reservas legais, auxiliando proprietários rurais a cumprirem suas obrigações perante as normas exigidas pela legislação ambiental. Dentre projetos 
com a finalidade da recuperação destas áreas e do comprometimento dos proprietários rurais em sua conservação e manutenção está o projeto Reviva Confusão.

De acordo com CABRAL \& OLIVEIRA (2009), o projeto Reviva Confusão fora instituído como um projeto de educação ambiental voltado para a recuperação da bacia do ribeirão da Confusão, sendo este parte do Projeto de Recuperação de Matas Ciliares (PRMC). Consoante a Secretaria Estadual do Meio Ambiente (2009, apud CABRAL \& OLIVEIRA, 2009), o PRMC tem por objetivo a promoção da recuperação de matas ciliares no Estado de São Paulo, como também o dever de contribuir para a ampliação da cobertura vegetal de 13,9\% para $20 \%$ do território estadual, o estabelecimento de parcerias com a Secretaria da Agricultura e Abastecimento, de Saneamento e Energia, juntamente com sindicatos rurais, cooperativas e municípios.

Segundo os autores supracitados (CABRAL \& OLIVEIRA, 2009), o projeto Reviva Confusão, entretanto, fora concebido inicialmente após um acordo firmado por um Termo de Ajuste de Conduta (TAC) entre o Ministério Público e a Fazenda Sant'Anna, ao que o proprietário assumiu o comprometimento na recuperação das matas ciliares existentes em sua propriedade. Este proprietário, após discussões e acordos, propôs a formação de um Conselho entre sua fazenda, o Ministério Público, a Prefeitura de Rancharia, o Sindicato Rural de Rancharia, a Secretaria de Meio Ambiente do Estado de São Paulo e a Coordenadoria de Assistência Técnica Integral, com a finalidade de recuperar toda a bacia hidrográfica do ribeirão da Confusão, surgindo assim, o projeto Reviva Confusão.

Não só deve-se levar em conta a questão ecológica, como também todos os fatores socioeconômicos dos processos de desenvolvimento, um fator importante para a realização deste projeto se dá justamente a voluntariedade dos proprietários no comprometimento da recuperação destas áreas degradadas, já que o projeto tem por finalidade ampliar os benefícios ambientais e econômicos que sua biodiversidade deverá proporcionar aos moradores da bacia. Dessa forma, a restauração de áreas de preservação permanente resulta em um auxílio não somente à proteção dos recursos hídricos da bacia do ribeirão da Confusão, como também a recuperação de toda a biodiversidade da região. No ano de 2009 fora realizado, como atividades de educação ambiental, o plantio simbólico das primeiras mudas do reflorestamento em uma nascente na cabeceira da bacia. Este plantio teve o apoio de duas escolas primárias da cidade de Rancharia, dando-se em uma propriedade da cabeceira do ribeirão da Confusão. A Figura 1 
demonstra parte da cabeceira, juntamente com a área antes do plantio de mudas para o reflorestamento, área localizada ao Rancho K.T. Espero.

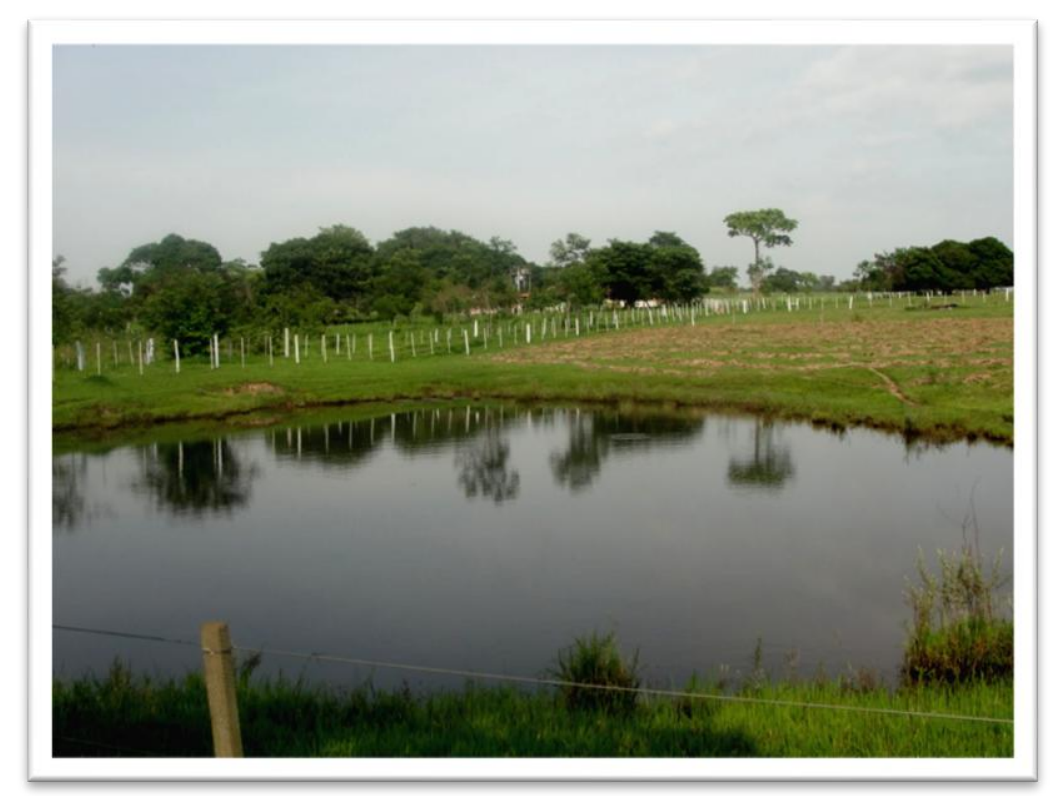

Figura 1. Propriedade Rancho K.T. Espero à que consta a cabeceira do ribeirão da Confusão (2009)

Localizada entre as coordenadas UTM 7539553 - 7573500 km N e 492990 - 526800 km E, a bacia do ribeirão está situada no Município de Rancharia, apresentando uma área total a superfície de 46.206,72 hectares. Por meio de análises de imagens de Satélite é possível examinar diferentes fisionomias vegetacionais, além de áreas de vegetação protegidas por Lei. Ao que diz respeito à legislação, deve-se observar primeiramente as áreas de preservação permanente, e, em seguida, a existência ou não de vegetação, podendo corresponder à área de reserva florestal legal ou, eventualmente, vegetação protegida pela Lei da Mata Atlântica.

De acordo com o mapa de vegetação do Brasil do IBGE (1993), a área que a bacia ocupa está situada na porção de Floresta Estacional Semidecidual. Este tipo de vegetação está presente no Grupo de Vegetação do Domínio da Mata Atlântica - DMA, segundo a resolução CONAMA 92 e a Lei n. 11.428/2. A área em questão apresenta um tipo de vegetação integrante deste grupo, que tem por maior representante, na região do Pontal do Paranapanema, a Reserva do Parque Estadual Morro do Diabo, além dos fragmentos da Estação Ecológica Micro-Leão-Preto (Água Sumida, Santa Maria, Ponte Branca e Tucano). Na bacia do ribeirão da Confusão, o bioma apresenta porções de transição para a Zona de Tensão Ecológica, ou seja, o cerrado, possuindo espécies da fauna ao qual necessitam de uma área extensa para proliferarem, por conta disto, somente por meio da ampliação das áreas de matas e a interconexão de diferentes fragmentos 
por meio de corredores biológicos, as áreas de preservação permanente e reservas legais em propriedades rurais, se faz possível à preservação destas espécies e de seu habitat. É essencial, portanto, que à observação da legislação ambiental, quando referente às áreas de preservação permanente e reserva legal, para a constituição dos corredores ecológicos na região da bacia, contribuindo para sua sustentabilidade.

\section{METODOLOGIA}

A elaboração deste trabalho deu-se por meio de análises de pareceres técnicos produzidos pelo Ministério Público do Estado de São Paulo em vistorias e levantamento de dados pertencentes à bacia do ribeirão Confusão, assim como vistorias in loco no mês de Julho de 2013. A localização da bacia, juntamente com seu perímetro, foram obtidas por meio de imagens de satélite, com a escala 1:110.000. A imagem utilizada em questão foi provida de satélite LANDSAT, 7 / ETM +, ao qual foi fornecida pelo INPE, correspondendo à órbita pontos 222-75, datada de 22 de julho de 2007. Por meio de análises da imagem foram elaboradas cartas aos quais correspondem: a análise temporal da vegetação e a localização das áreas de preservação permanente. Uma vez tendo obtido as cartas, juntamente com observações em campo, foi possível diagnosticar as condições a que as áreas encontram-se atualmente, além do seu progresso ao decorrer dos últimos anos desde a implementação do projeto Reviva Confusão.

\section{RESULTADOS}

Por meio das análises efetuadas se fez possível levantar um número suficiente de informações que caracterizassem a bacia do ribeirão da Confusão e identificasse suas áreas de vegetação. A bacia apresenta uma área total de 46.206,72 ha, ao que apresenta como áreas úmidas um total de $2.084,15$ ha, área de preservação permanente um total de 4.291,00 ha, sendo que desta área, $2.647,00$ ha correspondem ao ribeirão da Confusão e o restante de 1.644 ha ao ribeirão Bartira, afluente do ribeirão da Confusão. A área de vegetação natural (bioma) da Mata Atlântica, com porções de transição para a Zona de Tensão Ecológica (cerrado) é composta em $2.440,97$ ha.

Estão presentes no interior da bacia áreas brejosas (nascentes) ao longo de seus canais, o que impõe a presença de áreas de preservação permanente com uma distância mínima de 50 metros de largura logo após estas áreas úmidas. É possível notar que, em alguns dos trechos de corpos d'água existe a presença de planícies aluviais, das quais impõe um trecho de área de 
preservação permanente de ao menos 100 metros de largura. Outras situações, ao qual ocorrem em meio a encostas, há o afloramento do lençol freático, que resulta em níveis brejosos, para estas condições se faz necessário a aplicação de áreas de proteção de até 50 metros de largura. Estes parâmetros, previamente estabelecidos por Lei, são de extrema importância para a manutenção do ecossistema e sua biodiversidade, uma vez que devem conter coberturas vegetais ao longo de suas faixas.

A Figura 2 a seguir apresenta as coberturas vegetacionais encontradas na bacia do ribeirão da Confusão. Deve-se destacar que, do total de remanescentes de vegetação natural, 30 estão presentes na Fazenda Brasilândia do Tatu, cobrindo uma área total de 861,43 hectares, ao que destes, 23 remanescentes possuem uma área abaixo de 100 hectares. Assim, no interior da bacia de drenagem há uma área de 2.440,97 ha de vegetação arbórea nativa, correspondendo a $5,28 \%$ da área total da bacia do ribeirão da Confusão.

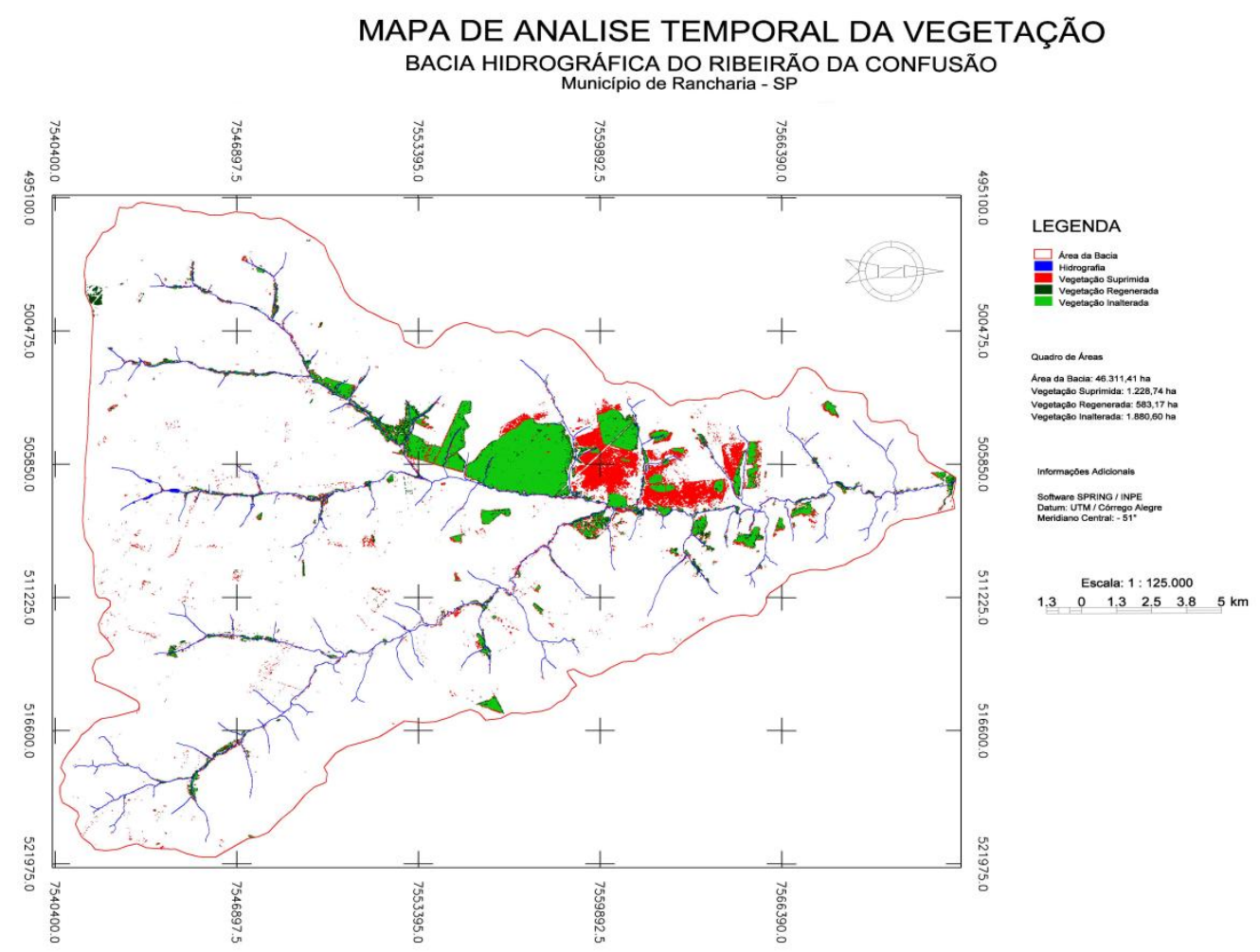

Figura 2 - Carta de análise temporal da vegetação da bacia do ribeirão da Confusão Fonte: CABRAL \& OLIVEIRA, 2009

As vegetações que cobrem as áreas de preservação permanente são as seguintes: vegetação nativa, eventual plantio de cana-de-açúcar, outras culturas e pastagem. Ao restante da bacia, contidas em seu interior, estão localizadas as áreas úmidas, encontradas principalmente em cabeceiras de drenagem, nas quais se situam os campos úmidos. Quanto às propriedades 
presentes na bacia, nove foram objetos de um TAC (Termo de Ajustamento de Conduta), tendo por finalidade o comprometimento em recuperar suas áreas de preservação permanentes. Durante vistorias in loco a bacia do ribeirão da Confusão, constatou-se um avanço positivo no que se refere às áreas das quais se discutiu a implementação de vegetação nativa sobre área de preservação permanente, com um avanço em boa parte das áreas protegidas. As Figuras 3 e 4 apresentam algumas áreas utilizadas para o plantio, com cerca de 2 a 3 anos de vida, comprometimento derivado das políticas de recuperação ambiental da bacia por parte do projeto Reviva Confusão.

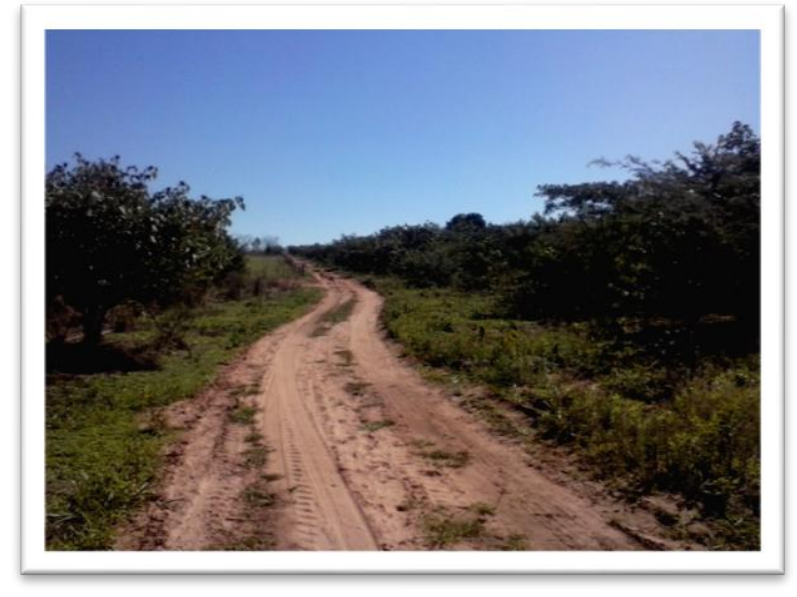

Figura 3. Espécies de plantas em áreas de preservação permanente e de reserva legal da bacia (2013)

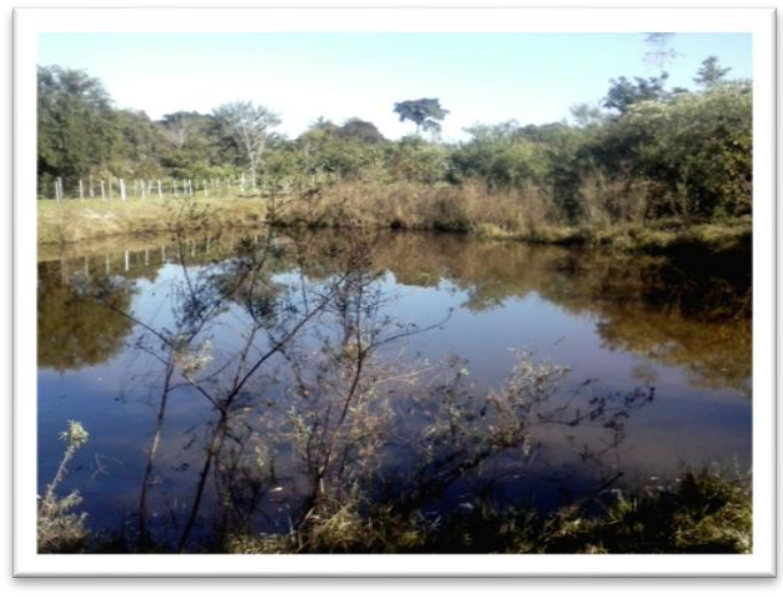

Figura 4. Área da propriedade K.T. Espero cercada por matas resultantes do plantio do projeto (2013)

\section{DISCUSSÃO}

É possível observar que a grande maioria das áreas de preservação permanente estão em uso e degradada, constatando que há certa conservação apenas naquelas das quais as APPs estão contíguas ou situando-se no interior de remanescentes florestais. Quando se aplica aquilo exigido por âmbitos legislativos à bacia, desde que se considerem as informações apresentadas anteriormente, é possível a constatação de que não há conservação total das áreas de preservação permanente localizadas em seu interior, sendo evidente a ocupação destas áreas, com culturas diversas, além do pastoreio de animais. Assim, considera-se a ocorrência de falta de conservação das matas ciliares ou riparias na bacia, muito menos a presença de reserva florestal legal em grande parte das propriedades rurais, localizadas em seu interior. A necessidade está na realização do cumprimento destas normas, de forma a que se consiga o isolamento destas áreas e sua recuperação. A importância de instituírem-se áreas de preservação permanente, juntamente 
com áreas de reserva legal em propriedades localizadas na bacia é evidente, tendo em vista a escassez de biodiversidade presente na região.

Expandindo estas características, irá promover um ambiente biodiverso e sustentável, de forma a que garanta melhores qualidades ambientais para os moradores e culturas presentes na bacia. Nota-se, portanto, um comprometimento maior na recuperação destas áreas no que diz respeito às condições anteriores ao projeto Reviva Confusão. Por fim, é possível constatar de que o meio físico não apresenta alterações significativas do ano de 2007 para o ano de 2013, no entanto observa-se que parte da recuperação destas áreas de preservação permanente estão ainda em processo de restauração, apresentando em algumas destas áreas, certa dificuldade em desenvolver-se por conta das condições a que o solo se encontra.

\section{CONCLUSÃO}

Este trabalho teve por finalidade levantar informações a respeito de condições das áreas de preservação permanente e de reserva legal, evidenciando suas importâncias em aspectos legislativos e ambientais, de forma a que passem a instituir corredores ecológicos na região da bacia do ribeirão da Confusão, com a finalidade de dar sustentabilidade ao meio, conservando sua biodiversidade e seus recursos naturais, garantindo um melhor aproveitamento para os proprietários da região. Boa parte destas áreas encontra-se cercada, livre de influências externas como atividades humanas ou então ao pastoreio de animais. As ações voltadas para a recuperação das matas ciliares na bacia, resultantes do projeto Reviva Confusão, demonstram a importância e incentivo a implementação de práticas semelhantes, pois contribuem para uma melhoria na qualidade ambiental não só dos recursos hídricos, como também em todo o meio físico e biótico da região.

\section{REFERÊNCIAS}

ABGE - Associação Brasileira de Geologia de Engenharia. Curso de geologia aplicada ao meio ambiente. São Paulo; ABGE-IPT, Série Meio Ambiente, 1995.

CABRAL, G. F. P.; OLIVEIRA, L. P. B. Uso de Técnincas de Sensoriamento Remoto Para Elaboração de Projeto de Recuperação de Mata Ciliar. Trabalho de Graduação em Engenharia Ambiental. UNESP. Presidente Prudente - SP. 2009.

DAVIDE, A. C.; FERREIRA, R. A.; FARIA, J. M. R.; BOTELHO, S. A.. Restauração de mata ciliar. Informe agropecuário. Belo Horizonte, v. no 207, p. 15-20 nov./dez., 2000. 
FRANCO J. G. DE O. Direito Ambiental - Matas Ciliares: Conteúdo Jurídico e Biodiversidade. Editora: Juruá Editora, 2005.

HENKE DE OLIVEIRA, C. Planejamento Ambiental na Cidade de São Carlos (SP) com ênfase nas áreas públicas e áreas verdes: diagnóstico e propostas. Dissertação de Mestrado, Centro de Ciências Biológicas e da Saúde, Universidade Federal de São Carlos. 1996.

VARJABEDIAN R. Ambiente Urbano e Áreas Verdes, Centro de Apoio Operacional das Promotorias de Justiça de Meio Ambiente. 2002. 